\title{
EXAMINATION OF ADAPTIVE AND MALADAPTIVE COGNITIVE EMOTION REGULATION STRATEGIES AS TRANSDIAGNOSTIC PROCESSES: ASSOCIATIONS WITH DIVERSE PSYCHOLOGICAL SYMPTOMS IN COLLEGE STUDENTS
}

\author{
Eva COSTA MARTINS ${ }^{1}$, Mónica FREIRE $^{1}$, Fernando FERREIRA-SANTOS $^{2}$ \\ ${ }^{1}$ Department of Social and Behavioural Sciences, ISMAI - Instituto Universitário da Maia \\ Av. Carlos Oliveira Campos, Castelo da Maia, 4475-690 Avioso S. Pedro, Portugal \\ E-mail: emartins@ismai.pt \\ ${ }^{2}$ Laboratory of Neuropsychophysiology, Faculty of Psychology and Education Sciences, \\ University of Porto, Portugal
}

\begin{abstract}
Maladaptive cognitive emotion regulation strategies have been reliably associated with psychopathology while lower consistency has been found for adaptive strategies. The extent to which adaptive strategies may function as protective factors was explored by analyzing how adaptive and maladaptive strategies relate to a diverse range of symptoms in 370 college students. We used the Cognitive Emotion Regulation Questionnaire (CERQ), the Brief Symptom Inventory, and the Difficulties in Emotion Regulation Scale. We developed a Portuguese version of CERQ. Different cognitive strategies predicted the nine psychological symptoms tested. At least one maladaptive strategy predicted each symptom dimension, while the same was not true for adaptive strategies. Our study supports: 1) cognitive emotion regulation as a transdiagnostic process that encompasses variability in the strategies underlying specific symptomatology; 2) that lower adaptive strategies sometimes predict psychological symptoms, but that higher maladaptive strategies are more consistently associated with psychopathology; 3) Portuguese CERQ's validity.
\end{abstract}

Key words: cognitive emotion regulation strategies, adaptive, maladaptive transdiagnostic, psychopathology

Emotion regulation can be defined as the intrinsic and extrinsic processes associated with the activation of an emotion and its management over time(Cole, Martin, \& Dennis, 2004; Gross, 2014). Emotion regulation strategies play a central role in determining human behavior since they have a pervasive impact on the functioning of an individual, influencing the adaptive or maladaptive role of a given emotional experience in a particular context (Cicchetti, Ganiban, \&
Barnett, 1991; Cole et al., 2004; Gross, 2014). Accordingly, emotion regulation has been referred to as a transdiagnostic process (Aldao, 2012; Sloan \& Kring, 2010), because many psychological disorders are characterized by problems related to emotion and emotion regulation (Werner \& Gross, 2010). Transdiagnostic processes are common factors that cut across different disorders and that underlie their development and/or course (Iverach, Menzies, \& Menzies, 2014; Sloan

DOI: $10.21909 /$ sp.2016.01.707 
\& Kring, 2010). Indeed, recent research on psychopathology has shifted away from analyzing factors that are specific to each individual psychological disorder to investigating common underlying dimensions of functioning (Caspi et al., 2014; Hong \& Cheung, 2014). For example, accumulating evidence shows that information processing biases are transdiagnostic processes because they occur in a variety of disorders, like anxiety, depression, oppositional defiant disorder or eating disorders (Aspen, Darcy, \& Lock, 2013; Fraire \& Ollendick, 2013). Specific to emotion regulation it is thought that maladaptive emotion regulation strategies (e.g., avoidance) increase the risk of psychopathology in general, while adaptive strategies (e.g., problem solving) function as protective factors (Aldao \& NolenHoeksema, 2010; Garnefski \& Kraaij, 2007). The present investigation was designed in accordance with this framework and aimed to explore the relation between adaptive and maladaptive cognitive emotion regulation strategies and a multitude of psychological symptoms.

There is some support for the distinction between adaptive (e.g., reappraisal) and maladaptive (e.g., rumination) cognitive emotion regulation strategies (Aldao, 2012; Domínguez-Sánchez et al., 2013; Jermann et al., 2006; Werner \& Gross, 2010, cf. Campos, Walle, Dahl, \& Main, 2011; Tuna \& Bozo, 2012). Indeed, maladaptive emotion regulation strategies seem to be reliably associated with increased psychopathology (Aldao \& Nolen-Hoeksema, 2012a; Joormann, Yoon, \& Siemer, 2010; Werner \& Gross, 2010). As for adaptive strategies, the converse would be expected (i.e., reliable negative associations with psychopathology) but this finding is less consistent. In some studies, no relation between adaptive strategies and psychopathology is reported (Domínguez-Sánchez et al., 2013; Ehring, Tuschen-Caffier, Schnülle, Fischer, \& Gross, 2010; Green et al., 2011). In a meta-analytic review, using normative and clinical samples, adaptive strategies were found to be associated with decreased psychopathology, but the associations had small to medium effect sizes (Aldao, Nolen-Hoeksema, \& Schweizer, 2010). This plethora of results influenced Aldao and Nolen-Hoeksema's (2010) transdiagnostic view of maladaptive cognitive emotion regulation, stating that the use of maladaptive strategies might play a more central role in psychopathology than not using adaptive strategies.

However, in certain circumstances, adaptive emotion regulation strategies may be relevant (Aldao \& Nolen-Hoeksema, 2012b) or even fundamental for understanding mental disorders. Evidence for this comes from Kelly, Lydecker, and Mazzeo (2012), who show that all adaptive strategies analyzed (with the exception of acceptance) moderated the effect of eating disorder on binge eating frequency, while none of the maladaptive ones did. Also, in a study on resilience in outpatients with depression and anxiety disorders, adaptive strategies were more strongly correlated with resilience than maladaptive strategies (Min, Yu, Lee, \& Chae, 2013).

Given the inconsistent findings on the relevance of adaptive emotion regulation for adaptation and psychopathology, the main objective of this study was to examine the role of adaptive cognitive emotion regulation as transdiagnostic processes. In order to accomplish this goal, the connections between adaptive cognitive emotion regulation strategies and a wide range of psycho- 
logical symptoms were analyzed. In previous transdiagnostic studies the number of symptoms or disorders included was small, as well as the number of adaptive cognitive strategies tested (e.g., Aldao \& NolenHoeksema, 2010). In order to address these limitations, we compared nine psychological symptom dimensions and five adaptive cognitive emotion strategies whilst also analyzing four maladaptive cognitive strategies (see the Method section). We used a normative student sample, as it has been previously done in studies exploring cognitive emotion regulation as a transdiagnostic process (Aldao \& Nolen-Hoeksema, 2010), since it samples the population range of both normal and clinical participants (whether or not referred for treatment).

Many self-report instruments have been designed to assess emotion regulation in adults, such as the Difficulties in Emotion Regulation Scale (DERS; Gratz \& Roemer, 2004), and the Emotion Regulation Questionnaire (Gross \& John, 2003). However, most instruments do not assess a wide range of cognitive emotion regulation strategies. But, the Cognitive Emotion Regulation Questionnaire (CERQ; Garnefski et al., 2001; Garnefski \& Kraaij, 2007) does provide an extended coverage of cognitive strategies capturing both attentional (e.g., rumination) and cognitive change (e.g., positive refocusing) processes. This instrument is in line with the cognitive components of Gross's (2014) model of emotion regulation. This author describes a process model of emotion regulation that highlights five families of emotion regulation strategies that emerge along the different stages of the generation of an emotional experience.

The first two families, situation selection and situation modification, are aimed at changing the environment that leads to the emergence of the emotion. Next, attentional deployment and cognitive change refer to strategies directed at regulating emotions without actually changing the environment. They may be broadly classified as cognitive strategies of emotion regulation since they are believed to be part of the cognitive "black box" (Gross \& Thompson, 2007).

Attentional deployment involves the redirection of attention within a given situation leading to regulation of the emotional experience. One classical example of this is rumination (Garnefski, Kraaij, \& Spinhoven, 2001), in which a person heightens hers or his emotion by continuously thinking and evaluating several aspects associated with the situation that activated the emotion. Another example, to diminish emotion intensity, is distraction (Werner \& Gross, 2010) defined by the redirection of attention from the event associated with the emergence of emotion (e.g., I am trapped inside the elevator) to other events (e.g., review mentally the shopping list while waiting for the technician to open the elevator door). If the new event is a positive one (e.g., think about how lovely was the last trip to the countryside), it is called positive refocusing (Garnefski et al., 2001).

Cognitive change refers to changing how one thinks either about the situation itself or about one's capacity to manage the demands it poses, i.e., altering the situation's emotional significance by changing how it is appraised (Gross \& Thompson, 2007). One example is positive reappraisal (Garnefski et al., 2001), that is, when someone attaches a positive meaning to a negative event in terms of personal growth (e.g., almost dying helped me learn to appreciate life better).

Finally, the last family of emotion regulation strategies in the emotion-generative pro- 
cess, after response tendencies have been initiated, is response modulation. This refers to directly influencing the emotion's physiological, experiential, or behavioral components.

As CERQ assesses both attentional and cognitive change emotion regulation families, this instrument is particularly valuable for research on cognitive emotion regulation, which explains why it has been translated into many different languages. Furthermore, the validity and original factor structure of the CERQ have been successfully replicated across samples in several countries (Domínguez-Sánchez et al., 2013; Jermann et al., 2006; Martin \& Dahlen, 2005; Tuna \& Bozo, 2012; Zhu et al., 2008).

Given the inexistence of a similar instrument in Portugal, a specific objective of this investigation was to translate the CERQ and to validate its psychometric properties: factor structure, internal consistency, and criterion validity (by relating CERQ-Portuguese with emotion dysregulation). Following Gross's (2014) process model of emotion regulation, cognitive emotion regulation is part of a variety of strategies described by Gross. Therefore, we expected that a global measure of emotional dysregulation would be associated with more maladaptive and less adaptive cognitive emotion regulation strategies.

\section{Method}

\section{Participants}

The sample consisted of 370 college students (60.3\% female) with majors in Psychology and Management recruited in two Portuguese Universities from the Porto metropolitan area. Ages ranged from 18 to 60 years
$(M=23.42, S D=6.98)$. Prospective participants were approached during class by a research assistant, informed about the study objectives and procedures, and asked about their interest in participating.

\section{Procedure}

The administration of a socio-demographic questionnaire, CERQ-Portuguese (CERQ-P), Difficulties in Emotion Regulation Scale (DERS), and Brief Symptom Inventory (BSI), was part of a larger research project which included other questionnaires. All participants were tested individually during class. Anonymity was granted for all participants.

\section{Instruments}

Cognitive Emotion Regulation Questionnaire

CERQ (Garnefski et al., 2001; Garnefski \& Kraaij, 2007) is a 36-item self-report questionnaire that assesses the use of cognitive emotion regulation strategies after experiencing negative life events or situations. It is composed of nine subscales representing different emotion regulation strategies, which may be classified as adaptive and maladaptive (Garnefski et al., 2001; Garnefski \& Kraaij, 2007). The maladaptive strategies are: selfblame (thoughts of blaming yourself for what you have experienced), rumination (thinking all the time about the feelings and thoughts associated with the negative event), catastrophizing (explicitly emphasizing the terror of the experience), and other-blame (thoughts of putting the blame for what you have experienced on others). The adaptive emotion regulation scales are: acceptance 
(thoughts of resigning to what has happened), putting into perspective (thoughts of playing down the seriousness of the event when compared to other events), positive refocusing (thinking of other, pleasant matters instead of the actual event), refocus on planning (thinking about what steps to take in order to deal with the event), positive reappraisal (thinking of attaching a positive meaning to the event in terms of personal growth).

CERQ is rated on a 5-point Likert scale ranging from 1 (almost never) to 5 (almost always). Each subscale score is obtained by summing the individual item scores that correspond to the related subscale (four items each). The score might range from 4 to a total of 20 . Higher scores on the subscales represent greater frequency of engaging in the corresponding emotion regulation strategy.

The psychometric properties of the CERQ have been found to be good, with factorial and criterion-related validity, good internal consistency and acceptable test-retest reliability (e.g., Garnefski \& Kraaij, 2007; Tuna \& Bozo, 2012).

\section{Translation}

The Portuguese version of CERQ (CERQP) was developed using the English version (devised by CERQ's original authors) through the back-translation method (Hambleton, 2005). First, the original version was translated into Portuguese by ECM and questions that arouse during the translation were discussed with CERQ's author Nadia Garnefski. Next, the Portuguese version was back-translated into English by another fluent speaker in Portuguese and English. Finally, the original version of the CERQ was compared with the back-translation. When discrepancies emerged in the back-translation, translators worked alongside until a consensus was reached. A test of the prefinal version was conducted with two adult participants with an interview to determine comprehension of each question or difficulties in understanding any of the wording. Minor adjustments were made to the final version of the questionnaire.

\section{Difficulties in Emotion Regulation Scale}

DERS (Gratz \& Roemer, 2004)) assesses the typical levels of emotion dysregulation across six domains: non-acceptance of negative emotions, inability to engage in goaldirected behaviors when experiencing negative emotions, difficulties controlling impulsive behaviors when experiencing negative emotions, limited access to emotion regulation strategies that are perceived as effective, lack of emotional awareness, and lack of emotional clarity. It contains 36 items rated on a 5-point Likert scale ranging from 1 (almost never applies to me) to 5 (almost always applies to me). Higher scores on this scale represent more emotion dysregulation. The Portuguese version used had high internal consistency, $\alpha=.93$, good test-retest reliability, $r=.88$, and adequate construct and predictive validity (Coutinho, Ribeiro, Ferreirinha, \& Dias, 2010).

\section{Brief Symptom Inventory}

BSI (Derogatis \& Melisaratos, 1983) is a self-report questionnaire developed to assess clinically relevant psychological symptoms. It contains 53 items rated on a 5-point scale of distress from 0 (not at all) to 4 (extremely). It assesses nine psychological symptom dimensions: somatization (psy- 
chological distress arising from perception of bodily dysfunction: complaints focused on autonomic nervous system functioning, aches and pains, and discomfort localized in the gross musculature), obsession-compulsion (thoughts and actions that are experienced as unremitting and irresistible by the patient but are of an ego-alien or unwanted nature), interpersonal sensitivity (feelings of personal inadequacy and inferiority during interpersonal interactions), depression (withdrawal of interest in life activities, loss of vital energy and feelings of hopelessness and futility), anxiety (restlessness, nervousness and tension and experiences reflecting free-floating anxiety and panic), hostility (in thoughts, feelings, and actions like: feelings of annoyance and irritability, urges to break things, frequent arguments and uncontrollable outbursts of temper), phobic anxiety (agoraphobic fears), paranoid ideation (paranoid mode of thought like projection, hostility, suspiciousness, centrality, and fear of loss of autonomy) and psychoticism (in most nonpsychiatric populations measures social alienation or schizoid alienated style). We used the Portuguese version that has good discriminant validity and therefore also allows for the classification of individuals regarding their probability of showing emotional problems (i.e., having a clinical diagnosis), based on their Positive Symptom Distress Index (PSDI). PSDI is the sum of the values of the items receiving non-zero responses divided by the Positive Symptom Total (PST). The PST is a count of all the items with non-zero responses. If a participant's score on PSDI is $\geq$ to 1.7, it is highly probable that that person has psychological problems (Canavarro, 2007). The Portuguese version of BSI (Canavarro, 2007) has also shown acceptable values for internal consistency in all dimensions, alphas $>$ .62 , and also adequate predictive validity.

\section{Data Analyses}

Initial missing value analysis showed that missing values in our database were low (the highest percentage was $1.6 \%$ of BSI's item 26). Therefore we used IBM SPSS 21 (IBM Corp., Armonk, NY, USA) regression method in order to impute the missing results.

The psychometric properties of the CERQ$P$ were analyzed by conducting a confirmatory factor analysis (CFA) using AMOS 20 (IBM Corp., Armonk, NY, USA). ACFA was carried out using maximum likelihood estimation in order to test for the expected nine factor solution and to determine the goodness of fit of the model, following the procedures used on the CFA of the original scale (Garnefski \& Kraaij, 2007). Next, using IBM SPSS 21, we analyzed CERQ-P's internal consistency with Cronbach's alpha. Pearson correlations were calculated among the CERQ-P subscales, as well as their relation with sex. The criterion-related validity of CERQ-P was assessed by conducting Pearson correlations of the CERQ-P subscales with a measure of emotion regulation difficulties (DERS). In order to examine the relation between adaptive strategies and psychological symptoms we conducted several regression analyses predicting each dimension of psychological symptoms (nine in total) or the presence/absence of emotional problems (i.e., probability of having a clinical diagnosis). Adaptive and maladaptive cognitive emotion regulation strategies were entered as predictors, and sex was controlled for. 


\section{Results}

\section{Preliminary Analysis: Study of CERQ Psychometric Properties}

Results for the nine-factor CFA showed an acceptable fit of the model to the data, $\chi^{2}(544)=1055.275, p<.001 ; \mathrm{CFI}=.902$; $\mathrm{RMSEA}=.050 ; \mathrm{IFI}=.904$. Standardized factor loadings were all significant, ranging from 0.23 (item 20 - acceptance) to 0.85 (item 18 other-blame) with a mean loading of 0.68 , suggesting that items generally converged meaningfully to the scales as predicted. Only three items had standardized factor loadings below .50: .23 (item 20-acceptance); .39 (item 19 -self-blame); 46 (item 27 - other-blame).

Cronbach's alpha coefficients computed for each scale (Table 1) ranged from .65 (selfblame) to .82 (positive refocusing). Selfblame and acceptance $(\alpha=.69)$ have acceptable internal reliability whilst all other scales have good internal consistency. Intercorrelations for CERQ-P scales are included in Table 2.

Table 1 Descriptive Statistics and Cronbach's $\alpha$ for Cognitive Emotion Regulation Questionnaire Scales $(N=370)$

\begin{tabular}{lcccccc}
\hline & Min & Max & Range & $M(S D)$ & $95 \%$ CI & Cronbach's $\alpha$ \\
\cline { 2 - 7 } Self-blame & 4 & 18 & 14 & $9.81(2.25)$ & {$[9.58,10.04]$} & .65 \\
Acceptance & 5 & 20 & 15 & $11.50(2.90)$ & {$[11.20,11.80]$} & .69 \\
Rumination & 4 & 20 & 16 & $12.03(3.19)$ & {$[11.70,12.35]$} & .76 \\
Positive refocusing & 4 & 20 & 16 & $11.14(3.32)$ & {$[10.80,11.48]$} & .82 \\
Refocus on planning & 7 & 20 & 13 & $14.25(2.89)$ & {$[13.96,14.55]$} & .80 \\
Positive reappraisal & 7 & 20 & 13 & $13.92(3.09)$ & {$[13.60,14.23]$} & .78 \\
Putting into perspective & 4 & 20 & 16 & $12.15(3.30)$ & {$[11.81,12.49]$} & .77 \\
Catastrophizing & 4 & 20 & 16 & $8.18(2.97)$ & {$[7.88,8.49]$} & .78 \\
Other-blame & 4 & 16 & 12 & $8.13(2.52)$ & {$[7.87,8.39]$} & .79 \\
\hline
\end{tabular}

Table 2 Descriptive Statistics for Brief Symptom Inventory (BSI) and Difficulties in Emotion Regulation Scale (DERS) $(N=370)$

\begin{tabular}{lccccc}
\hline & Min & Max & Range & $M(S D)$ & $95 \%$ CI \\
\cline { 2 - 5 } DERS total & & & & & \\
BSI scales & 41 & 143 & 102 & $79.1(18.72)$ & {$[77.05,81.08]$} \\
\hline Somatization & & & & & \\
Obsessive-compulsive & 0 & 3.4 & 3.4 & $.54(.62)$ & {$[.48, .61]$} \\
Interpersonal sensitivity & 0 & 3.5 & 3.5 & $1.07(.71)$ & {$[1,1.14]$} \\
Depression & 0 & 4 & 4 & $.87(.83)$ & {$[.79, .96]$} \\
Anxiety & 0 & 3.5 & 3.5 & $.89(.80)$ & {$[.80, .97]$} \\
Hostility & 0 & 4 & 4 & $.81(.66)$ & {$[.74, .88]$} \\
Phobic anxiety & 0 & 4 & 4 & $.90(.78)$ & {$[.82, .98]$} \\
Paranoid ideation & 0 & 4 & 4 & $.46(.59)$ & {$[.40, .52]$} \\
Psychoticism & 0 & 3.8 & 3.8 & $1.11(.78)$ & {$[1.03,1.19]$} \\
& 0 & 3.2 & 3.2 & $.73(.69)$ & {$[.66, .80]$} \\
\hline
\end{tabular}


Means and standard deviations of the CERQ subscales for the complete sample are displayed in Table 1. Self-blame, $r_{p b}=-.11$, $p=.04$, rumination $r_{p b}=.12, p=.018$ and otherblame $r_{p b}=-.13, p=.014$ were associated with sex (Table 2). Women reported lower selfblame ( $M=9.61, S D=2.14$ vs. men, $M=10.10$, $S D=2.39)$ and lower other-blame $(M=7.87$, $S D=2.32$ vs. men, $M=8.52, S D=2.77$ ) than men. Contrastingly, women reported higher rumination than men $(M=12.35, S D=3.28$ vs. men, $M=11.54, S D=2.99)$. Nevertheless, considering that the range of responses at each scale is at least 12 points (see Table 1) these differences are small.

Descriptive statistics for difficulties in emotion regulation and psychological problems can be found in Table 2 . Twenty eight percent $(N=105)$ of the sample had emotional problems (BSI's Positive Symptom Distress Index).

The relations between CERQ-P scales and DERS can be found in Table 3. As expected, maladaptive cognitive emotion regulation strategies were positively associated with higher emotion regulation difficulties (in descending order): catastrophizing, otherblame, self-blame, and rumination. Also, cognitive emotion regulation strategies classified as adaptive, namely refocus on planning, positive reappraisal, and positive refocusing, were associated with lower emotion regulation difficulties. No significant associations emerged with acceptance, and putting into perspective.

Relations between Adaptive Cognitive Emotion Regulation Strategies and Psychological Symptoms

Nine hierarchical linear regression analyses (each one attempting to separately pre- dict one scale of psychological symptoms from the BSI) and a hierarchical binary logistic regression analysis were carried out (Table 4). In all analyses sex was entered in the first step in order to control for its effect since we had previously found that it related to many of the psychopathology scales (Table 3). In the second step, all cognitive emotion regulation strategies were entered as predictors.

All nine overall models predicting different psychological symptoms were significant (Table 4) and sex emerged as a significant predictor. Being a woman is associated with reporting more symptoms in all scales. Somatization is predicted by using more selfblame, catastrophizing, and less refocus on planning. More obsessive-compulsive symptoms is associated with higher self-blame and other-blame. Higher interpersonal sensitivity is predicted by self-blame and catastrophizing. Depression is associated with the use of self-blame and catastrophizing, and less refocus on planning. Higher anxiety is predicted by more catastrophizing, rumination, self-blame, and less refocus on planning. Hostility is predicted by catastrophizing and other-blame. Phobic anxiety is associated with catastrophizing, selfblame, and other-blame. Higher paranoid ideation was only predicted by other-blame. Finally, psychoticism was predicted by selfblame, catastrophizing, and other-blame.

In summary, from the nine types of symptoms assessed only three were associated with a decreased use of adaptive emotion regulation. In contrast, higher usage of maladaptive cognitive emotion regulation strategies predicted all symptom dimensions.

The model predicting the presence of emotional problems (i.e., high probability of having a clinical diagnosis) was significant 


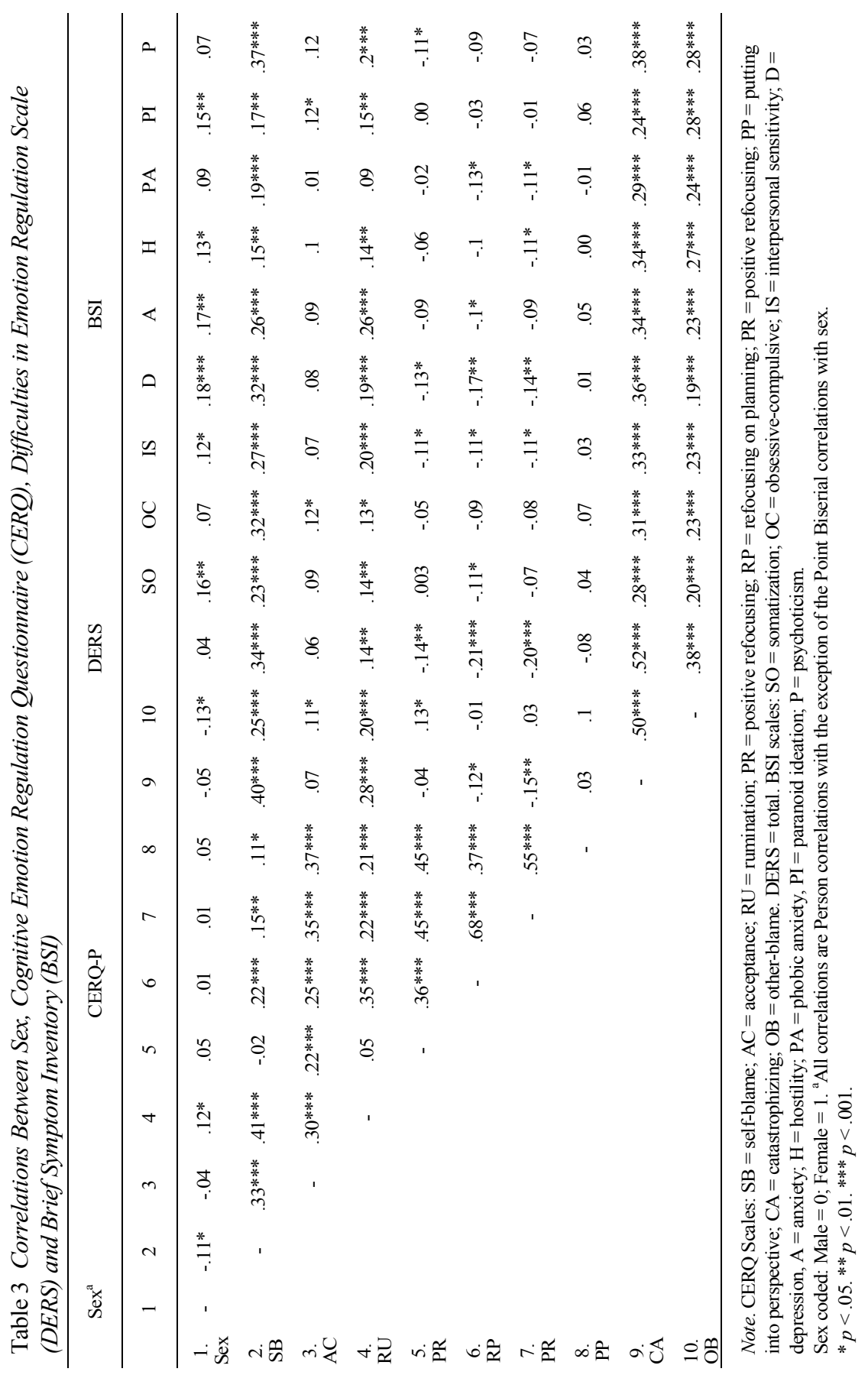




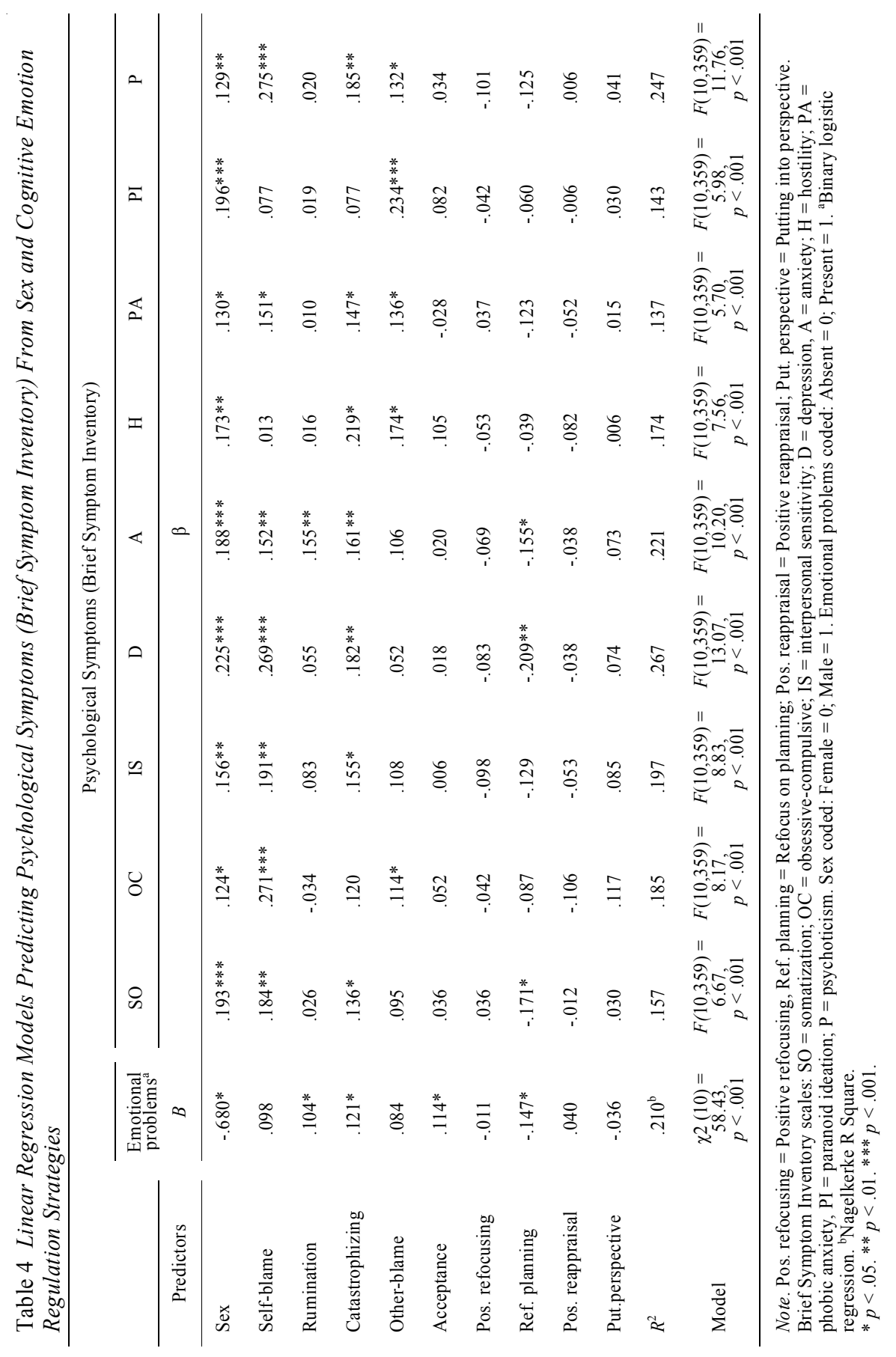


(Table 2). Sex emerged as a significant predictor. Being a woman is associated with the presence of emotional problems. Also, using more catastrophizing, acceptance and rumination and less refocus on planning predicts the emotional problems' group (Table 3). In summary, we found that two maladaptive cognitive emotion regulation strategies are associated with psychopathology, that the acceptance scale predicts psychopathology, and that one adaptive scale is negatively associated with emotion problems in the general population.

\section{Discussion}

In this investigation we examined the role of adaptive cognitive emotion regulation strategies as transdiagnostic processes in a student sample. Past research has given adaptive strategies a less predominant role in psychopathology when compared with maladaptive strategies (Aldao \& NolenHoeksema, 2010; Domínguez-Sánchez et al., 2013), while other studies have demonstrated the opposite (Kelly et al., 2012; Min et al., 2013). One main strong point of our research is that we compared differences in a wide range of symptoms while analyzing a diversity of adaptive and maladaptive strategies. By doing so, we tried to disentangle previous conclusions that may have been biased by limited sampling of psychological symptoms or adaptive strategies.

Our results seem to support the idea that adaptive strategies are protective factors of psychological symptoms, but also Aldao and Nolen-Hoeksema's (2010) transdiagnostic view of cognitive emotion regulation, stating that the use of maladaptive strategies might play a more central role in psychopathology than not using adaptive strategies.
Even though poor use of adaptive strategies predicted some psychological symptoms and the probability of having a clinical diagnosis, we found that maladaptive cognitive emotion regulation strategies, as a whole, were present across the variety of psychological symptoms tested. We found that at least one maladaptive cognitive strategy always emerged as predicting psychological symptoms (or being classified as having emotional problems). However, merely in 4 out of a total of 10 regressions (group with emotional problems, somatization, depression, and anxiety), did adaptive emotion regulation predict lower psychopathology. Actually, only refocuses on planning emerged as a significant predictor aside from acceptance (this scale will be discussed separately). Second, correlations between emotion dysregulation and maladaptive cognitive strategies were generally stronger than with adaptive strategies, and two adaptive strategies did not correlate with emotion dysregulation.

These results offer support for a lower use of adaptive strategies in psychopathology, contrasting with previous null results in the literature (Domínguez-Sánchez et al., 2013). Nevertheless, the findings also suggest that adaptive strategies are less relevant for psychopathology symptoms than maladaptive strategies. This might be due to the fact that strategies considered adaptive may be more or less appropriate depending on a) the situation the person is facing (Aldao \& NolenHoeksema, 2012a) and b) on the level of maladaptive strategies being used (Aldao \& Nolen-Hoeksema, 2012b). On the other hand, many of the maladaptive strategies may be more consistently maladaptive across situations (Aldao \& Nolen-Hoeksema, 2010). Nevertheless, the use of a maladaptive strategy 
by a given person in a specific situation may be functional and an adaptive strategy may be dysfunctional (Campos et al., 2011; Gross, 2014). Suppression is an example of this. It is generally considered a maladaptive strategy because it has been shown to maintain or even intensify negative emotions (see Werner \& Gross, 2010) and increase mortality risk (Chapman, Fiscella, Kawachi, Duberstein, \& Muennig, 2013). However, suppression may be functional if one faces a situation in which controlling the emotional display prevents a major negative event from happening (e.g., emotional suppression in a workplace discussion may prevent losing one's job). Also, although our results support a greater role for maladaptive emotion regulation strategies, the associations found with refocuses on planning are consistent with the literature in highlighting the importance of adaptive strategies as underlying mechanisms in psychopathology (Kelly et al., 2012; Min et al., 2013). Again, even a transdiagnostic perspective that emphasizes maladaptive emotion regulation indicates that adaptive emotion regulation strategies matter in particular circumstances (Aldao \& Nolen-Hoeksema, 2010, 2012a, 2012b). Therefore, the role of adaptive emotion regulation strategies requires further study. The selfreport measures used in the present study present limitations and future investigations would benefit from using contextual and multi-method approaches (Aldao, 2012; Campos et al., 2011) that would allow for a more detailed process-based examination of the role of adaptive emotion regulation strategies.

A comment about the acceptance scale is necessary. Even though it was originally designated as an adaptive scale, we found that higher levels of acceptance predicted belonging to the group with emotional problems and other studies have reported similar results (Martin \& Dahlen, 2005; Tuna \& Bozo, 2012; van Wijk-Herbrink, Andrea, \& Verheul, 2011; Zhu et al., 2008). It might be the case, as previously advanced, that participants may understand the acceptance items as a description of resigning passively to the distressing event, of feeling helpless and/or hopeless. In these circumstances, this may be a dysfunctional emotion regulatory strategy if the situation the person is facing can be altered (Tuna \& Bozo, 2012).

This investigation has also provided evidence regarding the relations between particular cognitive strategies and psychological symptoms. Many have called upon the importance of investigating the emotion regulation processes underlying psychopathological functioning (Aldao, 2012; Sloan \& Kring, 2010; Werner \& Gross, 2010), as these will have an important impact on our understanding of maladaptive trajectories and bring forward new foci for intervention. Although, as a whole, maladaptive cognitive strategies appear to fit the transdiagnostic label, considerable variability exists regarding the set of cognitive emotion regulation strategies that significantly predict each symptom dimension (and belonging to the group with emotional problems vs. general population). However, it should be noted that conclusions about the connections between specific cognitive emotion regulation strategies and psychopathology are only tentative, since we did not investigate a sample with clinical diagnosis.

Finally, this investigation also had a specific objective: to translate and psychometrically validate the CERQ in a Portuguese sample. We were able to confirm the original nine-factor structure of CERQ in our Portu- 
guese sample. It seems that CERQ-P is able to assess the nine different cognitive strategies as designed by the original authors of the questionnaire. We also obtained good levels of internal reliability for most scales (acceptable levels for self-blame, $\alpha=.65$, and acceptance, $\alpha=.69$ ). The criterion validity of CERQ-P was found to be good, since most associations between CERQ-P scales and difficulties in emotion regulation emerged in the expected direction. All maladaptive cognitive emotion regulation strategies were positively associated with higher emotion regulation difficulties. Additionally, three adaptive cognitive emotion regulation strategies (refocus on planning, positive reappraisal, and positive refocusing) were associated with lower emotion regulation difficulties. Only acceptance and putting into perspective did not correlate significantly with the global measure of emotion regulation. Interestingly, previous research has also found these scales to be less reliably associated with psychopathology (Tuna \& Bozo, 2012; Zhu et al., 2008). In summary, this investigation supports the cross-cultural validity and applicability of CERQ.

In summary, several conclusions can be derived from our results. As adaptive or maladaptive emotion regulation strategies predict a diverse range of psychological symptoms, this investigation offers additional support for emotion regulation, and specifically cognitive emotion regulation as transdiagnostic process. Also, we showed that lower adaptive emotion regulation strategies sometimes predict psychological symptoms, but that higher maladaptive strategies are more consistently associated with psychopathology. Finally, different sets of cognitive strategies may underlie the origin or the continuity of diverse psychopathologies, since most psychological symptom dimensions were predicted by different sets of cognitive strategies. Even maladaptive strategies differed from symptom to symptom. This supports a transdiagnostic view of emotion regulation that also encompasses variability in which specific cognitive emotion regulation strategies may underlie different psychological symptoms.

Received February 2, 2015

\section{References}

Aldao, A. (2012). Emotion regulation strategies as transdiagnostic processes: A closer look at the invariance of their form and function. Spanish Journal of Clinical Psychology - Revista de Psicopatología Y Psicología Clínica, 17(3), 261277.

Aldao, A., \& Nolen-Hoeksema, S. (2010). Specificity of cognitive emotion regulation strategies: A transdiagnostic examination. Behaviour Research and Therapy, 48(10), 974-983. doi: 10.1016/j.brat.2010.06.002

Aldao, A., \& Nolen-Hoeksema, S. (2012a). The influence of context on the implementation of adaptive emotion regulation strategies. Behaviour Research and Therapy, 50(7-8), 493-501. doi: 10.1016/j.brat.2012.04.004

Aldao, A., \& Nolen-Hoeksema, S. (2012b). When are adaptive strategies most predictive of psychopathology? Journal of Abnormal Psychology, 121(1), 276-281. doi:10.1037/a0023598

Aldao, A., Nolen-Hoeksema, S., \& Schweizer, S. (2010). Emotion-regulation strategies across psychopathology: A meta-analytic review. Clinical Psychology Review, 30(2), 217-237. doi:10.1016/ j.cpr.2009.11.004

Aspen, V., Darcy, A. M., \& Lock, J. (2013). A review of attention biases in women with eating disorders. Cognition \& Emotion, 27(5), 820-838. doi:10.1080/02699931.2012.749777

Campos, J. J., Walle, E. A., Dahl, A., \& Main, A. (2011). Reconceptualizing emotion regulation. Emotion Review, 3(1), 26-35. doi:10.1177/ 1754073910380975

Canavarro, M. C. (2007). Inventário de sintomas psicopatológicos (BSI). Uma revisăo crítica dos 
estudos realizados em Portugal [Brief Symptom Inventory (BSI). A critical review of portuguese studies]. In M. R. Simões, C. Machado, M. Gonçalves, \& L. Almeida (Eds.), Avaliação psicológica: Instrumentos validados para a população Portuguesa [Psychological Assessment: Instruments validated for the portuguese population] (pp. 305-327). Coimbra: Quarteto.

Caspi, A., Houts, R. M., Belsky, D. W., GoldmanMellor, S. J., Harrington, H., Israel, S., ... \& Moffitt, T. E. (2014). The p factor: One general psychopathology factor in the structure of psychiatric disorders? Clinical Psychological Science, 2(2), 119-137. doi:10.1177/ 2167702613497473

Chapman, B. P., Fiscella, K., Kawachi, I., Duberstein, P., \& Muennig, P. (2013). Emotion suppression and mortality risk over a 12 -year follow-up. Journal of Psychosomatic Research, 75(4), 381-385. doi:10.1016/j.jpsychores.2013. 07.014

Cicchetti, D., Ganiban, J., \& Barnett, D. C. (1991). Contributions from the study of high-risk populations to understanding the development of emotion regulation. In J. Garber \& K. A. Dodge (Eds.), The development of affect regulation and dysregulation (pp. 15-48). New York: Cambridge University Press.

Cole, P. M., Martin, S. E., \& Dennis, T. A. (2004). Emotion regulation as a scientific construct: Methodological challenges and directions for child development research. Child Development, 75(2), 317-333. doi:10.1111/j.1467-8624.2004. 00673.x

Coutinho, J., Ribeiro, E., Ferreirinha, R., \& Dias, P. (2010). Versăo portuguesa da Escala de Dificuldades de Regulaçăo Emocional e sua relaçăo com sintomas psicopatológicos [Portuguese version of Difficulties in Emotion Regulation Scale and its relation to psychological symptoms] Revista de Psiquiatria Clínica, 37(4), 145-151.

Derogatis, L. R. (1993). BSI Brief Symptom Inventory: Administration, scoring, and procedures manual (4th ed.). Minneapolis: National Computer Systems.

Derogatis, L. R., \& Melisaratos, N. (2009). The Brief Symptom Inventory: An introductory report. Psychological Medicine, 13(3), 595. doi:10.1017/S0033291700048017

Domínguez-Sánchez, F. J., Lasa-Aristu, A., Amor, P. J., \& Holgado-Tello, F. P. (2013). Psychometric properties of the Spanish version of the cognitive emotion regulation question- naire. Assessment, 20(2), 253-261. doi:10.1177/ 1073191110397274

Ehring, T., Tuschen-Caffier, B., Schnülle, J., Fischer, S., \& Gross, J. J. (2010). Emotion regulation and vulnerability to depression: Spontaneous versus instructed use of emotion suppression and reappraisal. Emotion, 10(4), 563-572. doi:10.1037/ a0019010

Fraire, M. G., \& Ollendick, T. H. (2013). Anxiety and oppositional defiant disorder: A transdiagnostic conceptualization. Clinical Psychology Review, 33(2), 229-240. doi:10.1016/j.cpr.2012. 11.004

Garnefski, N., \& Kraaij, V. (2007). The Cognitive Emotion Regulation Questionnaire. European Journal of Psychological Assessment, 23(3), 141-149. doi:10.1027/1015-5759.23.3. 141

Garnefski, N., Kraaij, V., \& Spinhoven, P. (2001). Negative life events, cognitive emotion regulation and emotional problems. Personality and Individual Differences, 30(8), 1311-1327. doi:10.1016/S0191-8869(00)00113-6

Gratz, K. L., \& Roemer, L. (2004). Multidimensional assessment of emotion regulation and dysregulation: Development, factor structure, and initial validation of the difficulties in emotion regulation scale. Journal of Psychopathology and Behavioral Assessment, 26(1), 41-54. doi:10. 1023/B:JOBA.0000007455.08539.94

Green, M. J., Lino, B. J., Hwang, E.-J., Sparks, A., James, C., \& Mitchell, P. B. (2011). Cognitive regulation of emotion in bipolar I disorder and unaffected biological relatives. Acta Psychiatrica Scandinavica, 124(4), 307-316. doi:10.1111/ j.1600-0447.2011.01718.x

Gross, J. J. (2014). Emotion regulation: Conceptual and empirical foundations. In J. J. Gross (Ed.), Handbook of emotion regulation (2 nd., pp. 320). New York: Guilford Press.

Gross, J. J., \& John, O. P. (2003). Individual differences in two emotion regulation processes: Implications for affect, relationships, and well-being. Journal of Personality and Social Psychology, 85(2), 348-362. doi:10.1037/0022-3514. 85.2 .348

Hambleton, R. K. (2005). Issues, designs, and technical guidelines for adapting tests into multiple languages and cultures. In R. K. Hambleton, P. F. Merenda, \& C. D. Spielberger (Eds.), Adapting educational and psychological tests for crosscultural assessment (pp. 3-38). New York: Psychology Press. 
Hong, R. Y., \& Cheung, M. W.-L. (2014). The structure of cognitive vulnerabilities to depression and anxiety: Evidence for a common core etiologic process based on a meta-analytic review. Clinical Psychological Science. doi:10. 1177/2167702614553789

Iverach, L., Menzies, R. G., \& Menzies, R. E. (2014). Death anxiety and its role in psychopathology: Reviewing the status of a transdiagnostic construct. Clinical Psychology Review, 34(7), 580593. doi: $10.1016 /$ j.cpr.2014.09.002

Jermann, F., Van der Linden, M., D’Acremont, M., \& Zermatten, A. (2006). Cognitive Emotion Regulation Questionnaire (CERQ). European Journal of Psychological Assessment, 22(2), 126131. doi:10.1027/1015-5759.22.2.126

Joormann, J., Yoon, K., \& Siemer, M. (2010). Cognition and emotion regulation. In A. Kring \& D Sloan (Eds.), Emotion Regulation and Psychopathology (pp. 174-203). The Guilford Press.

Kelly, N. R., Lydecker, J. A., \& Mazzeo, S. E. (2012). Positive cognitive coping strategies and binge eating in college women. Eating Behaviors, 13(3), 289-292. doi:10.1016/j. eatbeh.2012. 03.012

Martin, R. C., \& Dahlen, E. R. (2005). Cognitive emotion regulation in the prediction of depression, anxiety, stress, and anger. Personality and Individual Differences, 39(7), 1249-1260. doi: 10.1016/j.paid.2005.06.004

Min, J.-A., Yu, J. J., Lee, C.-U., \& Chae, J.-H. (2013). Cognitive emotion regulation strategies contributing to resilience in patients with depression and/or anxiety disorders. Comprehensive Psychiatry, 54(8), 1190-1197. doi:10.1016/ j.comppsych.2013.05.008

Sloan, D. M., \& Kring, A. M. (2010). Introduction and overview. In A. M. Kring \& D. M. Sloan (Eds.), Emotion regulation and psychopathology: A transdiagnostic approach to etiology and treatment (pp. 1-9). New York: Guilford Press.

Tuna, E., \& Bozo, Ö. (2012). Cognitive Emotion Regulation Questionnaire: Factor structure and psychometric properties of the Turkish version. Journal of Psychopathology and Behavioral Assessment, 34(4), 564-570. doi:10.1007/ s10862-012-9303-8

Van Wijk-Herbrink, M., Andrea, H., \& Verheul, R. (2011). Cognitive coping and defense styles in patients with personality disorders. Journal of Personality Dsorders, 25(5), 634-644. doi:10. 1521 /pedi.2011.25.5.634

Werner, K., \& Gross, J. J. (2010). Emotion regulation and psychopathology: A conceptual framework. In A. M. Kring \& D. M. Sloan (Eds.), Emotion regulation and psychopathology: A transdiagnostic approach to etiology and treatment (pp. 13-37). New York: Guilford Press.

Zhu, X., Auerbach, R. P., Yao, S., Abela, J. R. Z., Xiao, J., \& Tong, X. (2008). Psychometric properties of the Cognitive Emotion Regulation Questionnaire: Chinese version. Cognition \& Emotion, 22(2), 288-307. doi:10.1080/ 02699930701369035 